\title{
NMR Assignment of N-(1-adamantyl)-1-pentyl-1H-indazole-3-carboxamide Seized as Herbal Incense for the First Time in Italy
}

\section{Jussara Amato ${ }^{1}$, Nunzia Iaccarino ${ }^{1}$, Bruno Pagano ${ }^{1}$, Vincenzo Compagnone ${ }^{1}$, Fabiana Di Rosa ${ }^{2}$, Giuseppe} Peluso $^{2}$, Ettore Novellino ${ }^{1}$ and Antonio Randazzo ${ }^{*}$

${ }^{1}$ Department of Pharmacy, University of Naples Federico II, Naples, Italy

${ }^{2}$ Chemistry Section, Explosives and Flammable, Carabinieri Department Scientific Investigations, Viale Tor di Quinto 151, 00191 Rome, Italy

*Corresponding author: Antonio Randazzo, Department of Pharmacy, University of Naples Federico II, via D. Montesano 49, 80131 Napoli, Italy, E-mail: antonio.randazzo@unina.it

Citation: Jussara Amato, Nunzia Iaccarino, Bruno Pagano, Vincenzo Compagnone, Fabiana Di Rosa, et al. (2014) NMR Assignment of N-(1-adamantyl)-1-pentyl-1H-indazole-3-carboxamide Seized as Herbal Incense for the First Time in Italy. J Forensic Sci Criminol 2(1): 103. doi: 10.15744/2348-9804.1.403

Received Date: November 06, 2013 Accepted Date: February 10, 2014 Published Date: February 13, 2014

\begin{abstract}
The synthetic cannabinoid, $\mathrm{N}$-(1-adamantyl)-1-pentyl-1H-indazole-3-carboxamide, known also as AKB48 and/or APINACA, has been detected for the first time in herbal incense seized in Italy. Its structural characterization has been performed through gas chromatography-mass spectrometry (GC-MS) and high-resolution nuclear magnetic resonance (NMR) analysis. In order to favor an easier and faster identification of AKB48 in future investigations, NMR assignments in deuterated methanol and chloroform is also reported.
\end{abstract}

Keywords: NMR; GC-MS; Designer drug; Synthetic cannabinoid; Herbal incense

\section{Introduction}

Synthetic cannabinoids are chemicals that mimic the effect of $\Delta^{9}$-tetrahydrocannabinol $\left(\Delta^{9}\right.$-THC), which is the principal psychoactive constituent (cannabinoid) of the cannabis plant. These chemicals are often added to a mixture of dried plant matter (e.g. herbs) and sold for smoking with names such as "Herbal incense" or "Spice" [1,2]. Occasionally, they are also sold as powder and if so may be drunk as a tea. Such products were developed to be a legal alternative to cannabis [3], however many synthetic cannabinoids substances are now banned. Indeed, these products have received broad global attention due to their cannabimimetic effects and a number of countries have not been approved for human consumption in consideration of their potential health problems [4]. On the other hand, many synthetic cannabinoids have only recently been developed and there is very limited information available regarding their short and long-term effects [5].

Although the abuse of synthetic cannabinoids was first discovered in Europe, this phenomenon seems to be an issue now in almost all developed countries throughout the world [6]. Moreover, in response to control measures adopted, there is a strong tendency for the producers to quickly adapt to changes in legislations, by innovatively using similar compounds that are yet to be controlled.
Over recent years, tens of synthetic cannabinoids have been detected as psychoactive ingredients in herbal products or chemical powders around the world. In this frame, and following our continuous effort to oppose illegal drug trafficking [7], here we report the structural characterization of $\mathrm{N}-(1-$ adamantyl)-1-pentyl-1H-indazole-3-carboxamide (Figure 1), also known as AKB48 and/or APINACA, that has been detected for the first time in herbal incense seized in Italy. In order to favor an easier and faster identification of AKB48 in the future investigations, NMR assignments in deuterated methanol and chloroform is also reported.

\section{Materials and Methods}

\section{NMR spectroscopy}

${ }^{1} \mathrm{H}$-NMR spectra were acquired at $25{ }^{\circ} \mathrm{C}$ using 400 and 700 $\mathrm{MHz}$ Varian Unity Inova spectrometers equipped with a 5 $\mathrm{mm}{ }^{1} \mathrm{H}\left\{{ }^{13} \mathrm{C} /{ }^{15} \mathrm{~N}\right\}$ triple resonance probe. Spectra have been referred to $\mathrm{CHCl}_{3}\left(\delta_{\mathrm{H}}=7.26 \mathrm{ppm}\right), \mathrm{CHD}_{2} \mathrm{OD}\left(\delta_{\mathrm{H}}=3.31 \mathrm{ppm}\right)$, ${ }^{13} \mathrm{CD}_{3} \mathrm{OD}\left(\delta_{\mathrm{C}}=49 \mathrm{ppm}\right)$ and ${ }^{13} \mathrm{CHCl}_{3}\left(\delta_{\mathrm{C}}=77 \mathrm{ppm}\right)$ as internal standards. Standard pulse sequences were employed for COSY, TOCSY, HSQC and HMBC experiments. HSQC and HMBC were optimized for ${ }^{1} \mathrm{~J}_{\mathrm{C}-\mathrm{H}}=135 \mathrm{~Hz}$ and ${ }^{2,3} \mathrm{~J}_{\mathrm{C}-\mathrm{H}}=10 \mathrm{~Hz}$, respectively. 


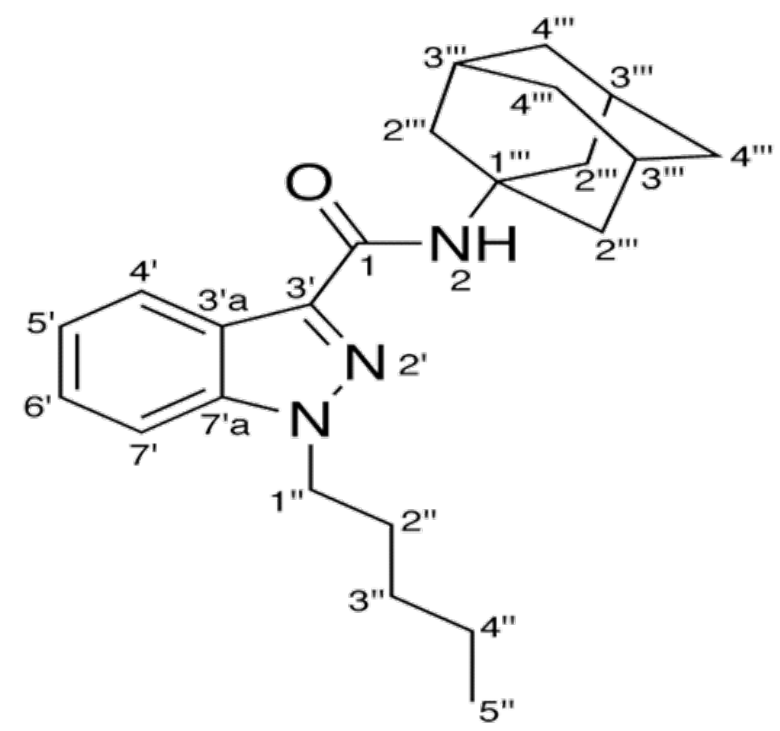

Figure 1: Chemical structure of N-(1-adamantyl)-1-pentyl-1H-indazole3-carboxamide (AKB48).

\section{GC-MS}

Seized samples were dissolved in absolute ethyl alcohol (Carlo Erba Reagenti, Italy) to a concentration of $1 \mathrm{mg} / \mathrm{mL}$. GC was performed with an Agilent 6890A gas chromatograph equipped with a quadrupole mass-selective detector (MSD) Agilent 5973N (Agilent Technologies). The MSD was operated in the electron ionization (EI) mode, with an ionization potential of $70 \mathrm{eV}$, a scan range of 40-550 amu. The GC was fitted with a $30 \mathrm{~m} \times 0.25 \mathrm{~mm}$ ID fused-silica capillary column coated with $0.25 \mu \mathrm{m} 5 \%$ diphenyl 95\% dimethylpolysiloxane stationary phase (HP5-ms, J\&W). The oven temperature was programmed as follows: initial temperature, $80{ }^{\circ} \mathrm{C}$; initial hold, $2 \mathrm{~min}$; program rate, $25^{\circ} \mathrm{C} / \mathrm{min}, 280^{\circ} \mathrm{C}$; hold, $15 \mathrm{~min}$. Column flow: $1 \mathrm{~mL} / \mathrm{min}$. The injector was operated in the split mode $(10: 1)$ at $280^{\circ} \mathrm{C}$. Injection vol. $1 \mu \mathrm{l}$.

\section{Results and Discussion}

Five transparent plastic bags containing each ca. $1.5 \mathrm{~g}$ of herbal incense were seized in October 2012 in the city of Latina (Italy) from Italian military police (Carabinieri). $1.5 \mathrm{~g}$ of sample were extracted for $1 \mathrm{~h}$ at room temperature with methanol. The insoluble residues were washed several times. The collected extracts were dried down providing $94.5 \mathrm{mg}$ of dry matter.

A small aliquot of the extract has been analyzed firstly by GC$\mathrm{MC}$ analysis. Basically, only one peak was observable in the total ion chromatogram (TIC) (Figure 2A), whose ion turned out to have $m / z 365$ (Figure $2 \mathrm{~B}$ ). A number of fragment ions were also observed, which were very diagnostic for characterizing the molecule. In particular the intense fragments at $\mathrm{m} / \mathrm{z}$ $337,308,294,215,150$ and 145 , along the molecular ion peak, allowed us to assume that the analyzed molecule is $\mathrm{N}-(1-$ adamantyl)-1-pentyl- $1 \mathrm{H}$-indazole-3-carboxamide (Figure 1), known also as AKB48 and/or APINACA. Part of the ion peaks could be interpreted as reported in Figure 2C. In particular, the ion fragments at $m / z 187,294$ and 308 correspond to the breaking of the bonds between $\mathrm{C} 1-\mathrm{C} 3$ ', $\mathrm{C} 1$ '"-N1' and $\mathrm{C} 1$ "-C2", respectively, whereas the ions at $m / z 135 / 230$ and $150 / 215$ are due to the breaking of the bonds C1"'-N2 and C1-N2, respectively.
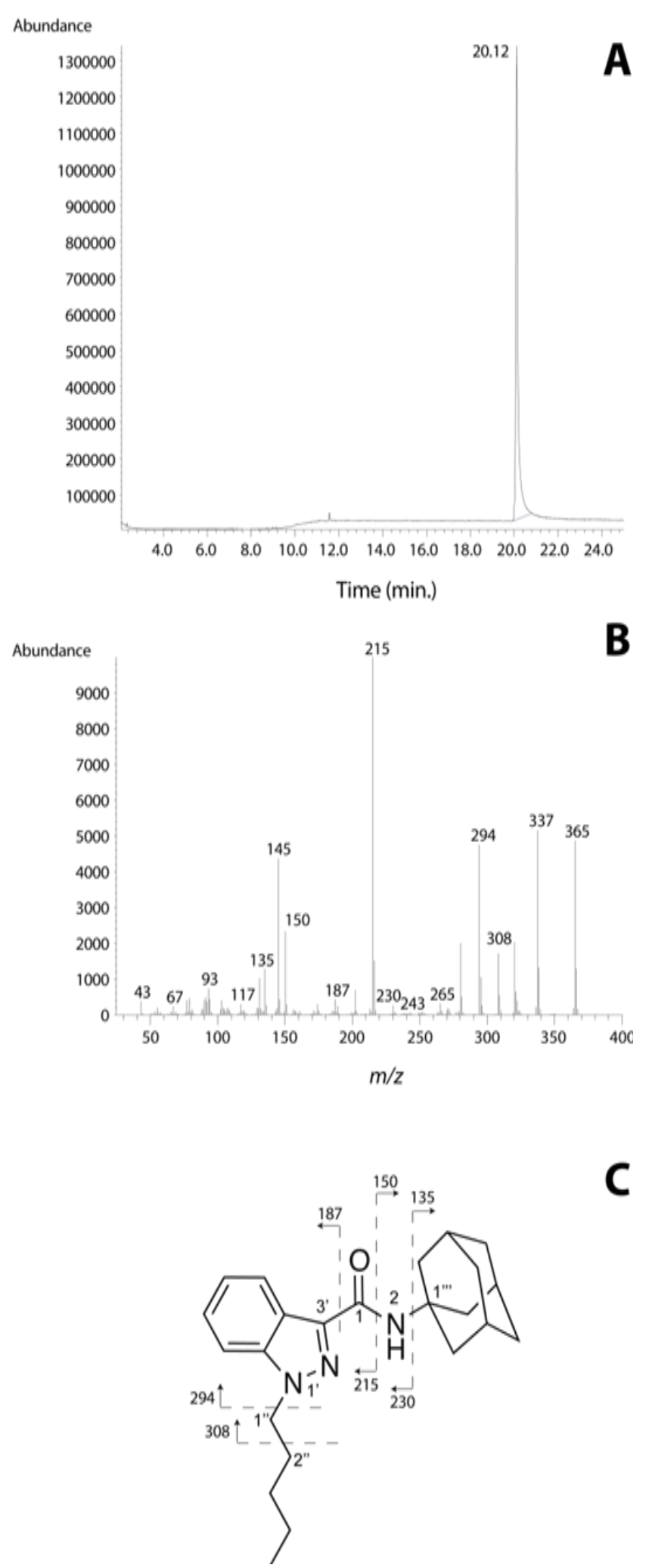

Figure 2: GC-MS analysis of AKB48. (A) Total ion chromatogram; (B) EI mass spectra of the detected peak at $20.12 \mathrm{~min}$; (C) Fragmentation pattern. 


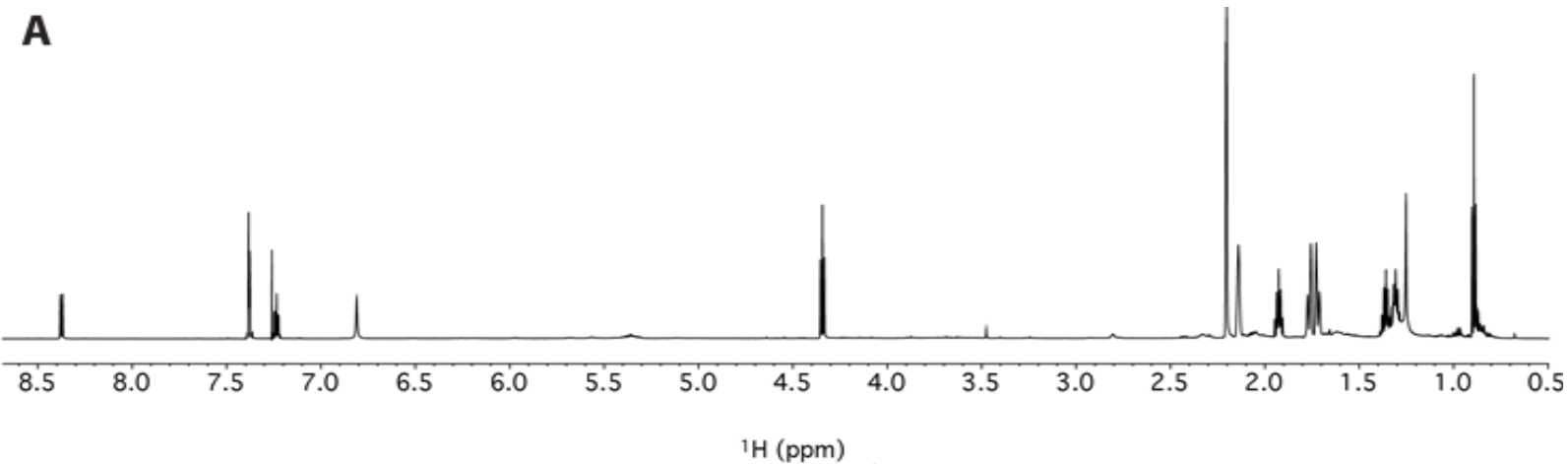

B

Figure 3: (A) ${ }^{1} \mathrm{H}$ - and (B) ${ }^{13} \mathrm{C}-\mathrm{NMR}$ spectra of $\mathrm{AKB} 48$ in $\mathrm{CDCl}_{3}\left(700 \mathrm{MHz} ; 25^{\circ} \mathrm{C}\right)$.

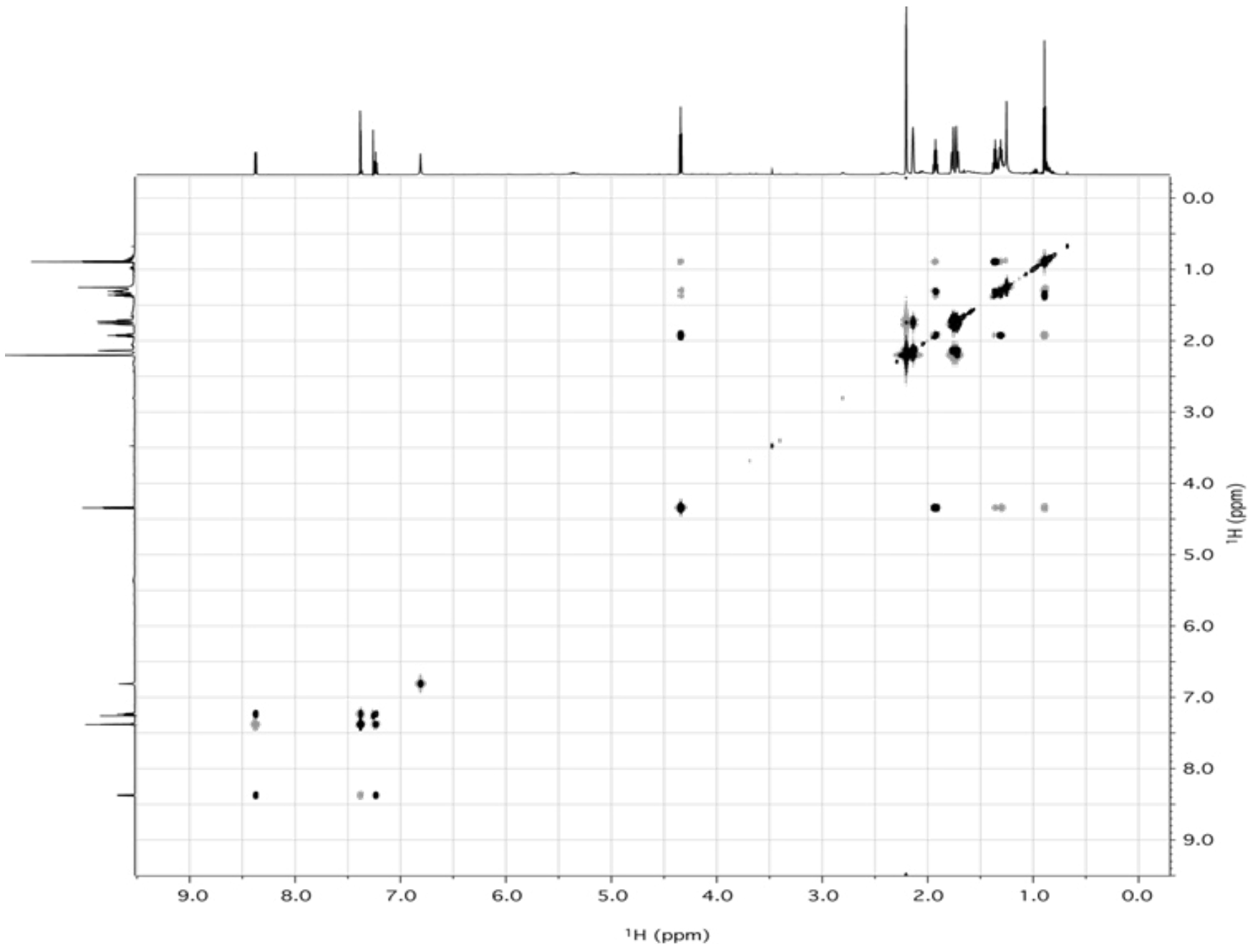

Figure 4: Superimposition of the COSY (black) and TOCSY (gray) spectra of AKB48 in $\mathrm{CDCl}_{3}\left(700 \mathrm{MHz} ; 25^{\circ} \mathrm{C}\right)$. 


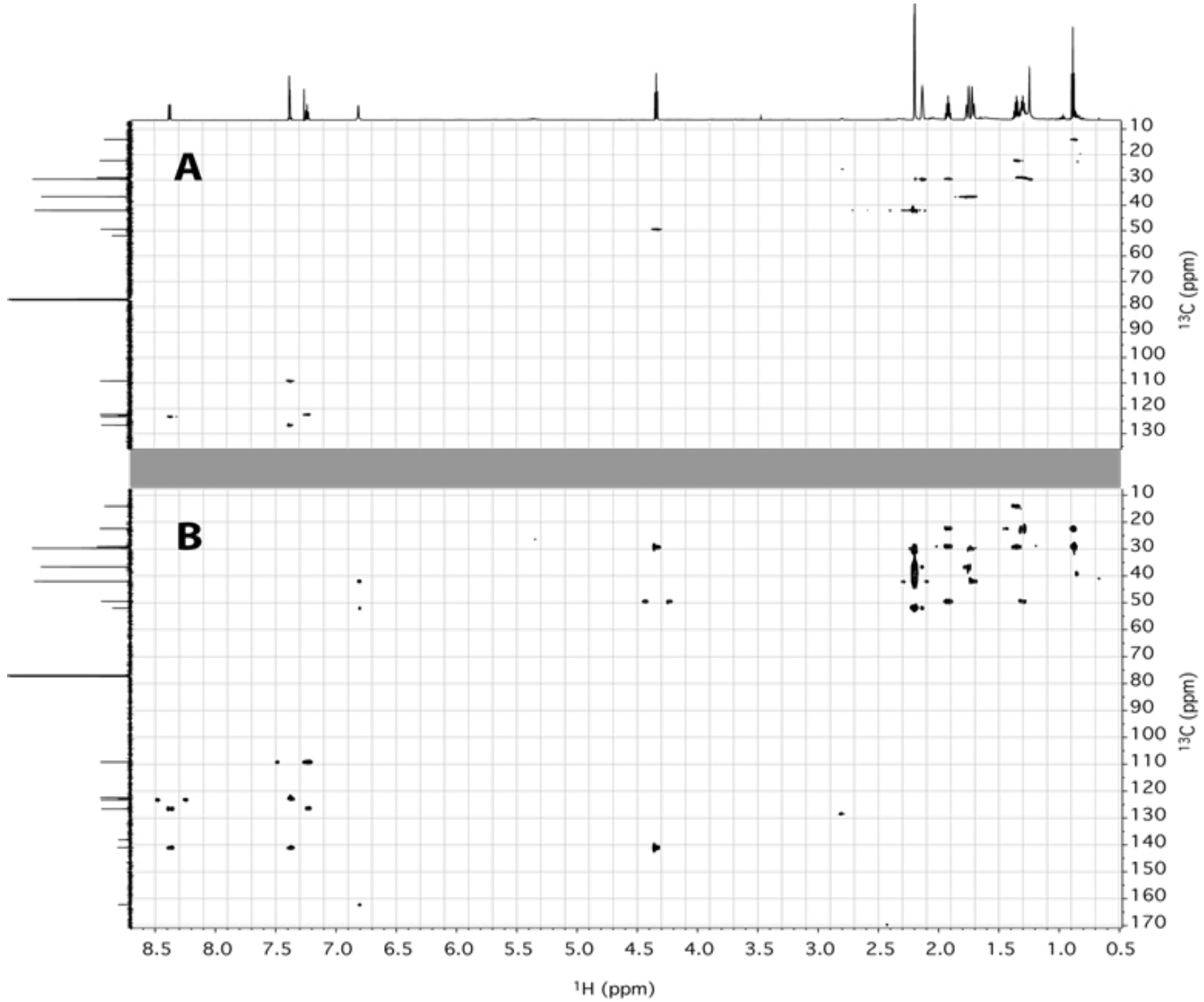

Figure 5: (A) HSQC and (B) $\mathrm{HMBC}$ spectra of $\mathrm{AKB} 48$ in $\mathrm{CDCl}_{3}\left(700 \mathrm{MHz}, 175 \mathrm{MHz} ; 25^{\circ} \mathrm{C}\right.$ ).

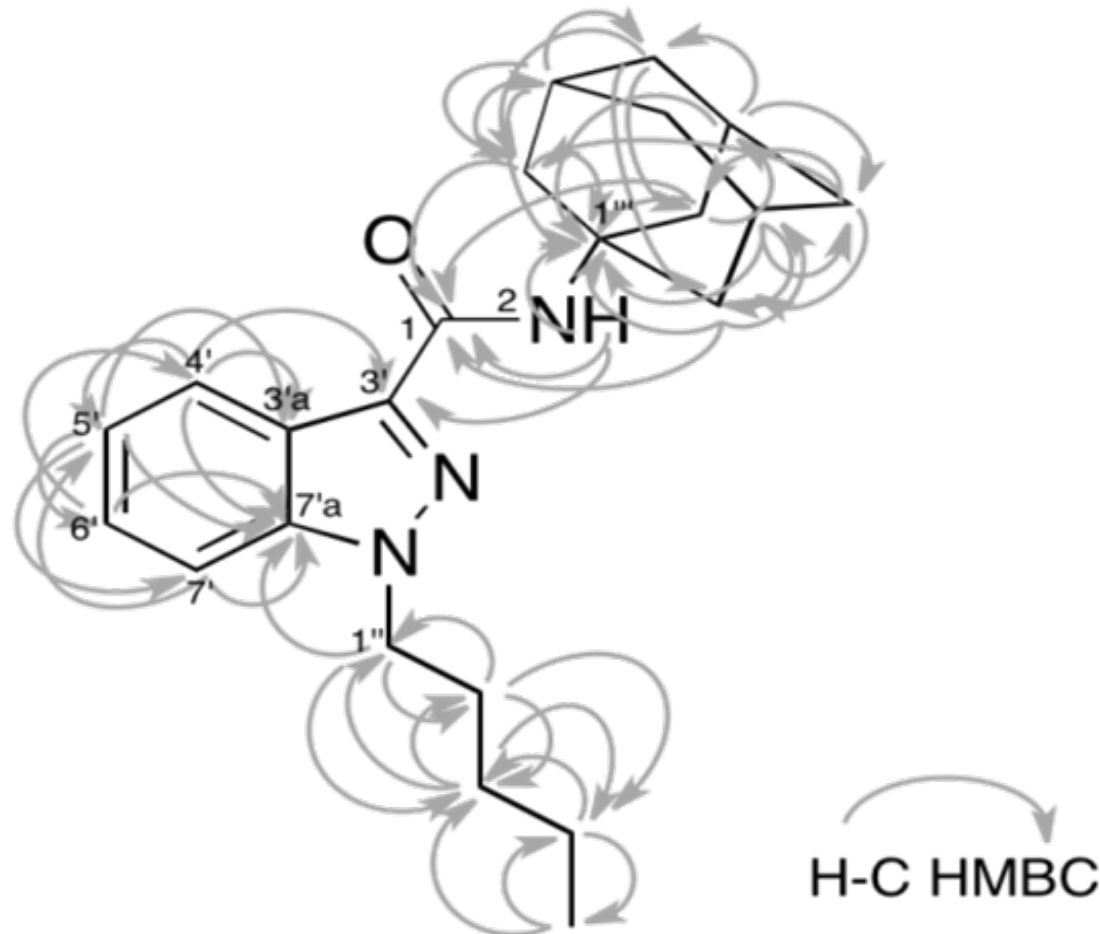




\begin{tabular}{|c|c|c|c|c|}
\hline & \multicolumn{2}{|c|}{$\mathrm{CD}_{3} \mathrm{Cl}$} & \multicolumn{2}{|c|}{$\mathrm{CD}_{3} \mathrm{OD}$} \\
\hline Atom & ${ }^{1} \mathrm{H} \delta$ (ppm) & ${ }^{13} \mathrm{C} \delta$ (ppm) & ${ }^{1} \mathrm{H} \delta$ (ppm) & ${ }^{13} \mathrm{C} \delta$ (ppm) \\
\hline 1 & - & 162.2 & - & 179.5 \\
\hline 2 & 6.81 & - & - & - \\
\hline $2^{\prime}$ & - & - & - & - \\
\hline 3' & - & 138.1 & - & 138.5 \\
\hline 3’a & - & 122.9 & - & 123.4 \\
\hline 4 ' & 8.37 & 123.3 & 8.19 & 122.9 \\
\hline 5 & 7.23 & 122.4 & 7.25 & 123.3 \\
\hline 6 & 7.38 & 126.7 & 7.43 & 127.6 \\
\hline $7^{\prime}$ & 7.37 & 109.2 & 7.58 & 110.6 \\
\hline 7’a & - & 141 & - & 142.3 \\
\hline $1 "$ & $4.342 \mathrm{H}$ & 49.5 & $4.442 \mathrm{H}$ & 50 \\
\hline 2" & $1.93 \mathrm{2H}$ & 29.6 & $1.922 \mathrm{H}$ & 30.3 \\
\hline 3" & $1.312 \mathrm{H}$ & 29.1 & $1.282 \mathrm{H}$ & 29.9 \\
\hline 4" & $1.362 \mathrm{H}$ & 22.4 & $1.352 \mathrm{H}$ & 23 \\
\hline 5" & $0.893 \mathrm{H}$ & 14.1 & $0.883 \mathrm{H}$ & 14.1 \\
\hline $1^{\prime \prime}$ & - & 52.2 & - & 53.2 \\
\hline 2"' & $2.202 \mathrm{H}$ & 42 & $2.232 \mathrm{H}$ & 36.3 \\
\hline 3"' & 2.13 & 29.7 & 1.6 & 26.5 \\
\hline 4"” & $1.72-1.76$ & 36.6 & 1.3 & 29.9 \\
\hline
\end{tabular}

10 methylenes (where two groups of three methylenes were magnetically equivalent in the adamantyl moiety). The pentyl moiety (C1"-C5") was easily characterized also using the COSY and TOCSY experiments. For the determination of the aromatic moiety, the HMBC moiety turned out to be particularly diagnostic, especially to assign the quaternary carbons C3', C3'a and C7'a. In fact, basing on the correlations with aromatic hydrogens 4 ' and $5^{\prime}$ it was possible to assign the carbon at position 3'a. Analogously, C3' was assigned by the connections with $\mathrm{H} 2$ and $\mathrm{H} 4$ ', and $\mathrm{C} 7$ 'a with the connections with H4, H5', H6, H7' and H1'. Finally, the adamantly moiety was also easily assigned taking into account the symmetry of the moiety (Figure 6).

\section{Conclusions}

Designer drugs are created to avoid the provisions of existing drug laws, usually by preparing analogs or derivatives of existing drugs by modifying their chemical structure. Most of these new illicit drugs are synthesized and trafficked prevalently for recreational use. The major efforts of illicit labs are focused on the synthesis of cannabinoids derivatives and the number of designer drugs is increasing exponentially all over the world. In particular, last year in Japan it has been seized for the first time a new synthetic cannabinoid identified as $\mathrm{N}$-(1-adamantyl)-1-pentyl-1H-indazole-3-carboxamide (Figure 1), known also as AKB48 and/or APINACA [8]. Its identification has been performed mainly by NMR and GCMS. In particular, the NMR assignment of AKB48 has been reported in deuterated benzene. Here, we have reported the finding of AKB48 in herbal incense seized for the first time outside Japan and its NMR characterization in both deuterated chloroform and methanol. Sharing of such information may be valuable for a fast and easy identification of this new cannabinoid to prevent its abuse worldwide.

\section{Acknowledgement}

Authors are grateful to "Centro Servizi Interdipartimentale di Analisi Strumentale (CSIAS)" of the University of Naples.

glance, important information. It is characterized by 17 signals. The signals at $\delta_{C} 29.7,36.6$ and $42.0 \mathrm{ppm}$ turned out to be particularly intense with respect of the other signals, indicating the presence of equivalent carbons in the molecule. The chemical shifts of those carbons, along with the total number of signals present in the spectrum, are consistent with the structure of AKB48. Also taking into consideration the aromatic spectral region $\left(\delta_{C} 105-145 \mathrm{ppm}\right)$, that is generally very diagnostic, the number and chemical shift of the signals are consistent with the structure of AKB48. In order to assign all resonances $\left({ }^{1} \mathrm{H}\right.$ and ${ }^{13} \mathrm{C}$ ) to the pertinent atom, bi-dimensional COSY (Figure 4), TOCSY (Figure 4), HSQC (Figure 5A) and HMBC (Figure 5B) experiments have been acquired and interpreted. In particular, we started to analyze the HSQC experiment since it provides information about which hydrogen is bound to which carbon. From this experiment, it was easy to detect the presence of 4 aromatic and 3 equivalent aliphatic methines, 1 methyl and

\section{References}

1. Piggee C (2009) Investigating a not-so-natural high. Anal Chem 81: 3205-7. 2. Penn HJ, Langman LJ, Unold D, Shields J, Nichols JH (2011) Detection of synthetic cannabinoids in herbal incense products. Clin Biochem 44: 1163-5. 3. Lindigkeit R, Boehme A, Eiserloh I, Luebbecke M, Wiggermann M, et al.(2009) Spice: a never ending story? Forensic Sci Int 191: 58-63.

4. Vardakou I, Pistos C, Spiliopoulou C (2010) Spice drugs as a new trend: mode of action, identification and legislation. Toxicol Lett 197: 157-62.

5. Seely KA, Lapoint J, Moran JH, Fattore L (2012) Spice drugs are more than harmless herbal blends: a review of the pharmacology and toxicology of synthetic cannabinoids. Prog Neuropsychopharmacol Biol Psychiatry 39: 234-43. 6. Spaderna M, Addy PH, D'Souza DC (2013) Spicing things up: synthetic cannabinoids. Psychopharmacology 228: 525-40.

7. Pagano B, Lauri I, De Tito S, Persico G, Chini MG, et al. (2013) Use of NMR in profiling of cocaine seizures. Forensic Sci Int 231: 120-4. 
8. Uchiyama N, Kawamura M, Kikura-Hanajiri R, Goda Y (2012) Identification of two new-type synthetic cannabinoids, N-(1-adamantyl)-1-pentyl-1Hindole-3-carboxamide (APICA) and $\mathrm{N}$-(1-adamantyl)-1-pentyl-1H-indazole3-carboxamide (APINACA), and detection of five synthetic cannabinoids, AM-1220, AM-2233, AM-1241, CB-13 (CRA-13), and AM-1248, as designer drugs in illegal products. Forensic Toxicol 30: 114-125.

9. Uchiyama N, Kawamura M, Kikura-Hanajiri R, Goda Y (2013) URB-754: a new class of designer drug and 12 synthetic cannabinoids detected in illegal products. Forensic Sci Int 227: 21-32.
10. Uchiyama N, Matsuda S, Kawamura M, Kikura-Hanajiri R, Goda Y (2013) Two new-type cannabimimetic quinolinyl carboxylates, QUPIC and QUCHIC, two new cannabimimetic carboxamide derivatives, ADB-FUBINACA and ADBICA, and five synthetic cannabinoids detected with a thiophene derivative $\alpha$-PVT and an opioid receptor agonist AH-7921 identified in illegal products. Forensic Toxicol 31: 223-240. 